Supporting Information

\title{
Reagentless Amperometric Pyruvate Biosensor Based on a Prussian Blue- and Enzyme Nanoparticle-Modified Screen-Printed Carbon Electrode
}

\author{
Dinakaran Thirumalai, ${ }^{\dagger}$ Seonghye Kim,,${ }^{\ddagger}$ Suhkmann Kim,,${ }^{*}+$ and Seung-Cheol Chang ${ }^{*} \dagger$ \\ ${ }^{\dagger}$ Department of Cogno-Mechatronics Engineering, Department of Optics and Mechatronics Engineering, \\ College of Nanoscience and Nanotechnology, Pusan National University, Busan 46241, Republic of \\ Korea \\ ${ }^{\ddagger}$ Department of Chemistry, Chemistry Institute for Functional Materials, Sustainable Utilization of \\ Photovoltaic Energy Research Center, Pusan National University, Busan, 46241, Republic of Korea
}




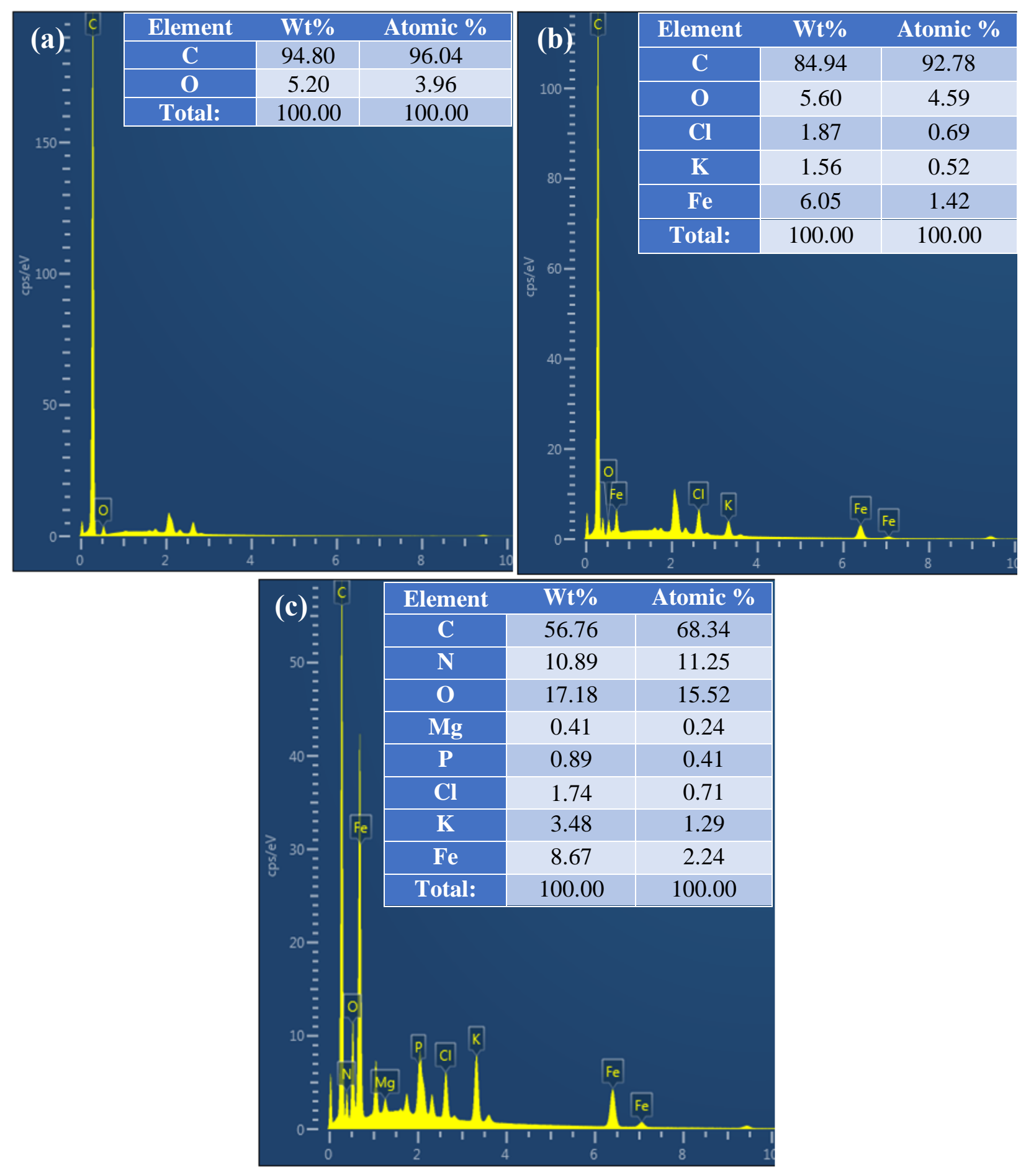

Figure S1. EDS spectrum analysis of (a) Bare SPCE, (b) PB/SPCE, and (c) PoxBNPs/PB/SPCE. 

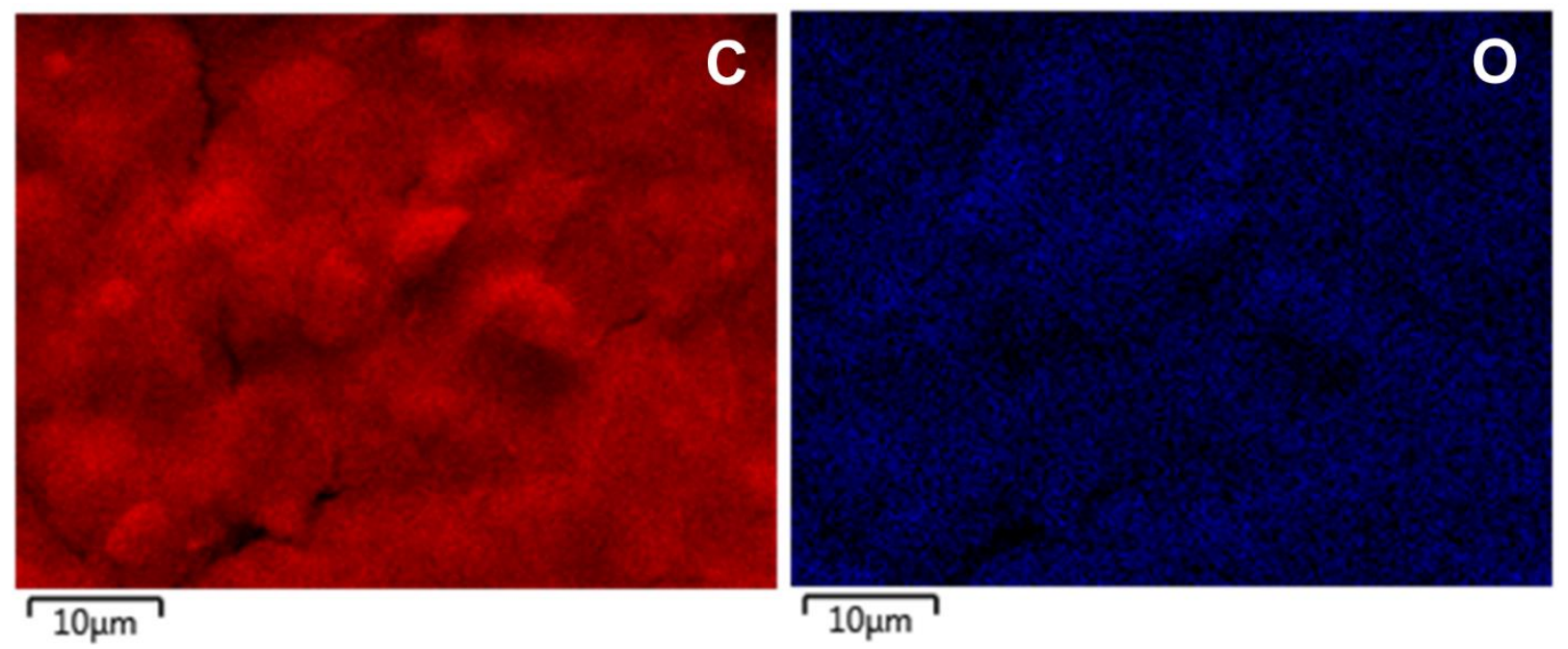

Figure S2. EDS elemental mapping of Bare SPCE. 


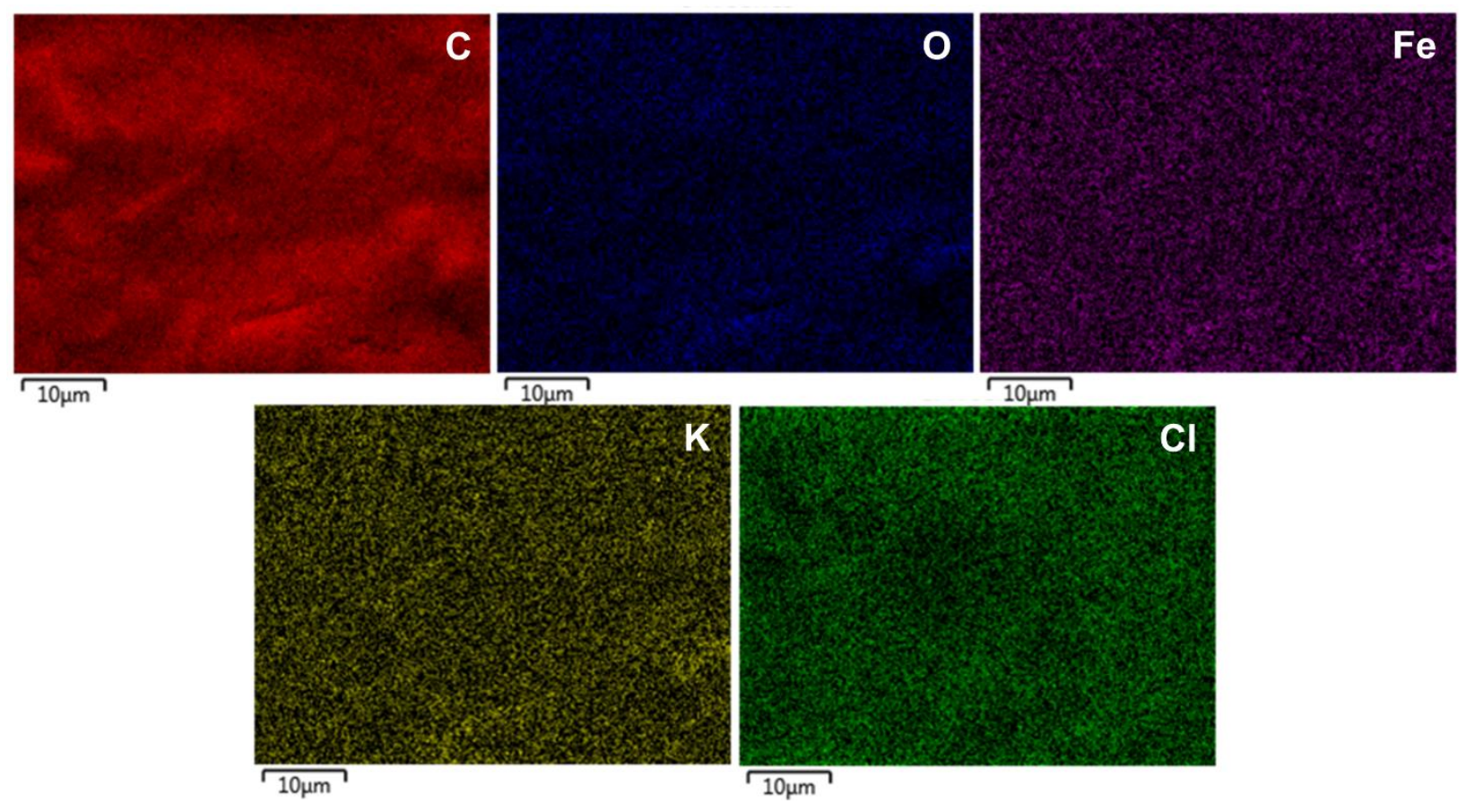

Figure S3. EDS elemental mapping of PB/SPCE. 


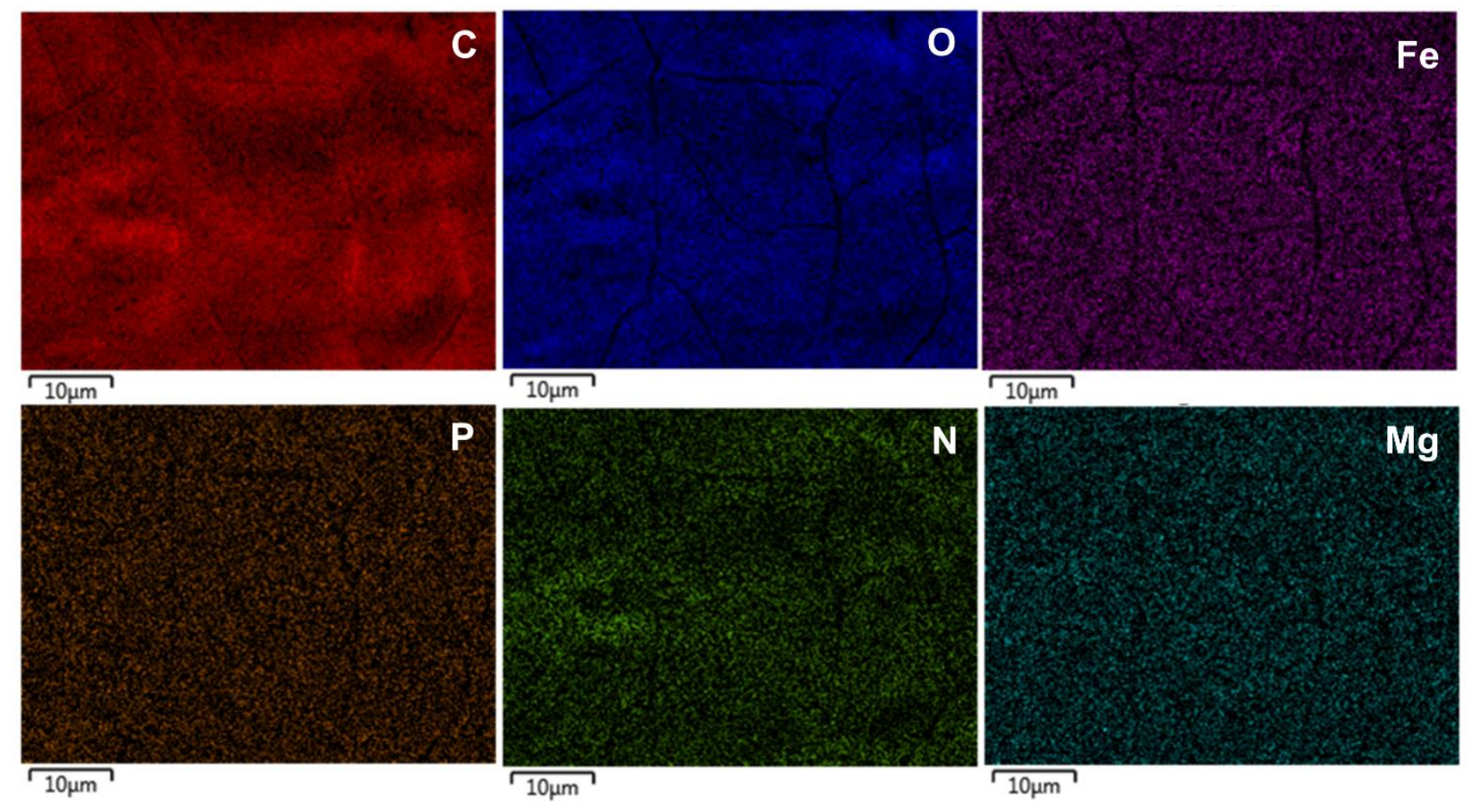

Figure S4. EDS elemental mapping of PoxBNPs/PB/SPCE. 
Table S1. A comparison of various analytical parameters of amperometric Py biosensors

\begin{tabular}{|c|c|c|c|c|c|c|c|}
\hline $\begin{array}{l}\text { Composition } \\
\text { of electrode }\end{array}$ & $\begin{array}{l}\text { Method of } \\
\text { immobiliza } \\
\text { tion }\end{array}$ & Reagent & $\begin{array}{l}\text { Working } \\
\text { potential } \\
\text { (V) vs. } \\
\mathrm{Ag} / \mathrm{AgCl}\end{array}$ & $\begin{array}{c}\text { Dynamic } \\
\text { linear } \\
\text { range } \\
(\mu \mathrm{M})\end{array}$ & $\begin{array}{l}\text { LOD } \\
(\mu \mathrm{M})\end{array}$ & $\begin{array}{c}\text { Sensitivity } \\
\left(\mu \mathrm{A} \mathrm{mM} \mathrm{m}^{-1}\right. \\
\left.\mathrm{cm}^{-2}\right)\end{array}$ & Ref. \\
\hline $\begin{array}{c}\text { PoxB/Polytyr } \\
\text { amine/platini } \\
\text { zed glassy } \\
\text { carb } \\
\text { electrode }\end{array}$ & Covalent & Reagent & +0.65 & $\begin{array}{l}100- \\
3000\end{array}$ & 50 & 6.0 & $\mathrm{~S} 1$ \\
\hline $\begin{array}{c}\text { PoxB/conduc } \\
\text { ting } \\
\text { polymer- } \\
\text { modified } \\
\text { electrode }\end{array}$ & Covalent & $\begin{array}{l}\text { Reagent- } \\
\text { less }\end{array}$ & $\begin{array}{l}+0.10 v s . \\
\quad \mathrm{SCE}\end{array}$ & $0-2500$ & 100 & 0.028 & $\mathrm{~S} 2$ \\
\hline $\begin{array}{c}\text { PoxB/3- } \\
\text { mercaptopro } \\
\text { pionic acid } \\
\text { and 6- } \\
\text { aminocaproic } \\
\text { acid/ Au } \\
\text { electrode }\end{array}$ & $\begin{array}{l}\text { Cross- } \\
\text { linking }\end{array}$ & Reagent & +0.03 & $1.0-10$ & 0.56 & - & $\mathrm{S} 3$ \\
\hline $\begin{array}{l}\text { PoxBNPs/Au } \\
\text { electrode }\end{array}$ & Covalent & Reagent & +0.28 & $\begin{array}{l}0.01- \\
5000\end{array}$ & 0.67 & - & $\mathrm{S} 4$ \\
\hline $\begin{array}{l}\text { PoxBNPs/pe } \\
\text { ncil graphite } \\
\text { electrode }\end{array}$ & Adsorption & Reagent & +0.10 & $\begin{array}{l}0.001- \\
6000\end{array}$ & 0.58 & - & S5 \\
\hline $\begin{array}{c}\text { PoxBNPs/PB } \\
\text { /SPCE }\end{array}$ & Adsorption & $\begin{array}{l}\text { Reagent- } \\
\text { less }\end{array}$ & -0.10 & $10-100$ & 0.91 & 40.8 & $\begin{array}{c}\text { Present } \\
\text { study }\end{array}$ \\
\hline
\end{tabular}




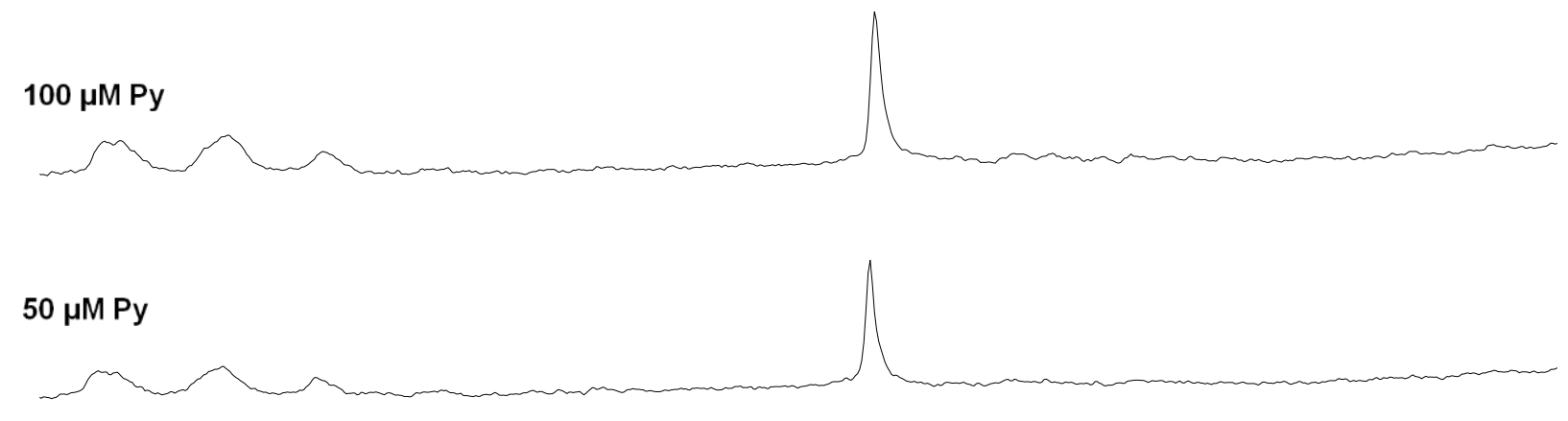

$10 \mu \mathrm{M}$ Py

$0 \mu \mathrm{M}$ Py

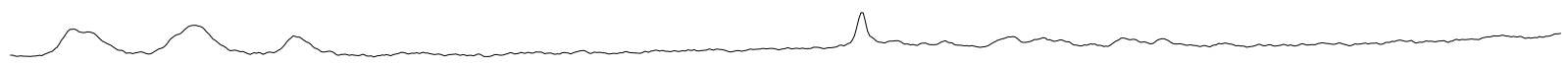

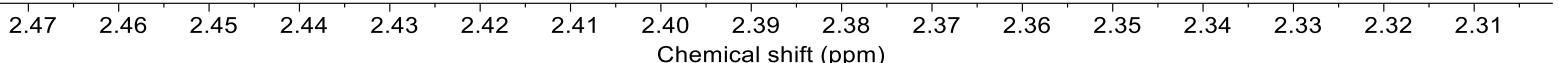

Figure S5. ${ }^{1} \mathrm{H}$ NMR spectrum of spiking experiment. The single resonance at $2.38 \mathrm{ppm}$ was the Py. This resonance increased depending on spiked concentration of Py. 


\section{References}

(S1) Situmorang, M.; Gooding, J. J.; Hibbert, D. B.; Barnett, D. The development of a pyruvate biosensor using electrodeposited polytyramine. Electroanalysis 2002, 14, 17-21.

(S2) Dang, L. A.; Haccoun, J.; Piro, B.; Pham, M. C. Reagentless recycling of pyruvate oxidase on a conducting polymer-modified electrode. Electrochimica Acta 2006, 51, 3934-3943.

(S3) Bayram, E.; Akyilmaz, E. A new pyruvate oxidase biosensor based on 3-mercaptopropionic acid/6-aminocaproic acid modified gold electrode. Artif. Cells Nanomed. Biotechnol. 2014, 42, 418-422.

(S4) Malik, M.; Chaudhary, R.; Pundir, C. S. An improved enzyme nnanoparticles based amperometric pyruvate biosensor for detection of pyruvate in serum. Enzyme Microb. Technol. 2019, 123, 30-38.

(S5) Malik, M.; Chaudhary, R.; Pundir, C. S. An amperometric pyruvate biosensor based on ppyruvate oxidase nanoparticles immobilized onto pencil graphite electrode. Process Biochem. 2020, 93, 12-20. 